\title{
A Flexão Nominal em Mattoso Câmara e Outras Análises
}

\author{
(Noun Inflection in Mattoso Câmara and Other Analyses)
}

Geraldo CINTRA

(USP)

\begin{abstract}
We analyze Joaquim Mattoso Câmara's description of noun inflection in Portuguese, initially pointing out the aspects in which differs from the traditional view. We them consider other approaches to the concepts involved in the view of renowned linguists both in Brazil and abroad. Finally, accepting alternative analyses, we demonstrate the possibility of reducing what is usually treated as noun inflection to only two derivational morphemes.
\end{abstract}

KEY-WORDS: Morphology; Noun inflection; Gender; Number.

REsumo: Analisamos a abordagem de Joaquim Mattoso Câmara Jr. para a flexão nominal em português, destacando inicialmente os aspectos em que sua análise difere da descrição tradicional. Consideramos, a seguir, outras abordagens dos conceitos envolvidos por parte de renomados lingüistas do Brasil e do exterior. Por fim, aceitando análises alternativas, demonstramos a possibilidade de redução das variações usualmente tratadas como flexão do substantivo a apenas dois morfemas derivacionais.

PaLAVRas-CHAVE: Morfologia; Flexão nominal; Gênero; Número.

\section{Introdução}

A análise de Joaquim Mattoso Câmara Jr. (JMC no restante deste texto) para a flexão nominal é tida como a análise padrão desse fenômeno em português. Embora muitas das idéias de JMC já tivessem sido publicadas em seus Princípios de Lingüística Geral (Mattoso Câmara 1941, 1954, 1959, 1964) e em artigos na revista Vozes, baseamo-nos aqui nessa análise em sua versão mais desenvolvida, como exposta em Problemas de Lingüística Descritiva (Mattoso Câmara 1969), Estrutura da Lingua Portuguesa (Mattoso Câmara 1970) e História e Estrutura da Lingua Portuguesa (Mattoso Câmara 1975), obras que puseram essas idéias ao alcance de um público consideravelmente mais amplo. 
As datas de publicação dessas obras não refletem a seqüência cronológica de sua elaboração. Como explica Naro (1976a: 86-87), "O trabalho mais destacado de Mattoso é sem dúvida The Portuguese Language, escrito em 1960 a convite da University of Chicago Press.” Esse texto, traduzido para o inglês pelo próprio Naro, foi publicado em 1972 (Mattoso Câmara 1972b), com o título The Portuguese Language. O original em português, contudo, só surgiu três anos mais tarde (Mattoso Câmara 1975). Completado e revisto pelo autor, é um texto mais representativo do que Mattoso Câmara (1969), que se destinava a alunos de graduação, ou do que Mattoso Câmara (1970), um pouco mais aprofundado mas admitidamente publicado incompleto após o falecimento do autor.

A obra ficou inacabada, porém. [..... liberou-se, todavia, a obra à publicação, tendo em vista tratar-se de contribuição de indiscutível valor, mesmo não cobrindo o campo total a que se propusera o autor. (Mattoso Câmara 1970, orelha)

Neste trabalho, partindo de uma breve exposição da análise de JMC e confrontando-a com a descrição tradicional, examinamos alguns outros pontos de vista teóricos sobre a interpretação das características de gênero e número para o português e para outras línguas, propondo, finalmente, uma reinterpretação da questão, fundamentada não apenas em características formais, mas também no emprego efetivo que dessas formas se faz no uso corrente da língua.

Mantemos, contudo, deliberadamente, a abordagem estruturalista adotada por JMC. Tal posicionamento não significa ignorar que "o estruturalismo descritivista foi logo suplementado na Lingüística Brasileira pela Teoria Gerativa" (Basílio 1999:53), nem subestimar os trabalhos decorrentes dessa orientação. Reflete apenas o intuito de demonstrar a possibilidade de outras análises sem mudança de modelo teórico.

\section{A análise de JMC}

O tratamento de JMC para a flexão nominal difere em natureza da abordagem tradicional por ser uma análise sincrônica formal, baseada na depreensão de formas mínimas associadas a características estruturais. Tem por base a língua em uso e não apenas o padrão literário nem uma modalidade idealizada, levando em consideração também a língua falada. Nos casos em que a fonologia interage com a morfologia, JMC particulariza 
sua análise para a fala do Rio de Janeiro (sua região de origem e de mais constante atuação), com eventuais referências a outras modalidades regionais. Distingue-se ainda esse tratamento por propor o estabelecimento de vogais temáticas nominais (à semelhança do que se verifica na classe dos verbos), pelo recurso ao conceito de morfema zero, e pela interpretação adotada em relação às características de gênero e de número.

\subsection{Vogais temáticas}

$\mathrm{Na}$ análise tradicional, as vogais finais $-o$ e $-a$ são consideradas marcadores de gênero, respectivamente masculino e feminino, tratados implicitamente como oposição eqüipolente, ${ }^{1}$ admitindo-se que a vogal $-e$ não está associada ao gênero. Assim, o gênero dos nomes seria definido morfologicamente para as palavras em $-o$ e $-a$, distribuindo-se outras palavras por ambos os gêneros. As gramáticas tradicionais são pródigas em exemplos e listas de exceções. (Cf. p. ex. Almeida 1963, cap. X; Cunha \& Cintra 1985, Cap. 8, entre outros)

Para JMC, a classe dos nomes está dividida em subclasses caracterizadas pela ocorrência ou não de um morfema classificatório, representado por uma vogal átona final, a vogal temática, sem relação com o conceito de gênero: "Não é costume nas nossas gramáticas estabelecer a mesma distinção para os nomes. Mas a conveniência de fazê-lo me parece inegável." (Mattoso Câmara 1970: 76)

Pode-se justificar a existência desses morfemas tanto sincronicamente, depreendendo-os da forma dos vocábulos, quanto diacronicamente, por ser a vogal temática a vogal da desinência de acusativo das três primeiras declinações a que se reduziu o sistema flexional de casos do latim, e é do acusativo que se originam as formas do português. Para vocábulos de outras origens essa análise se aplica por analogia, como em jangada, taba, esfiba, quitanda, maloca (com vogal temática -a), breque, greve, quibe, uísque (com vogal temática -e). As palavras terminadas em consoante são tratadas como temas em - $e$, com alomorfe zero da vogal temática no singular: "Os nomes terminados no singular em consoante pos-vocálica têm uma forma teórica em -e / i / átono final, que se deduz dos plurais." (Mattoso Câmara 1970:76)

\footnotetext{
A classificação das oposições é a de Trubtezkoy (1949).
} 
Convém acrescentar que por vezes essa vogal temática latente ocorre também em palavras derivadas, como em maremoto, malefício, em que seria difícil explicar de outra forma o fato de a vogal ser $-e$ e não outra..

Assim, não nos parecem justificadas as críticas de Duarte (2002), ${ }^{2}$ para quem a vogal temática nominal, "pelo menos considerando o plano superficial, não tem razão de ser" e carece de "uma motivação palpável, de ordem gramatical e distribucional". A seu ver, "[a]rgumenta-se que o estabelecimento do tema teórico tem base diacrônica, o que não é verdade", por não reconhecer a aplicação analógica a "palavras que têm o - $e$ apenas em sincronia". Considera o recurso à vogal temática "um artifício, que complica muito a descrição em nome da simplificação da formação do plural", sem reconhecer sua importância como identificadores de distribuição mórfica.

Já Cavaliere (2000), em posição diametralmente oposta à de Duarte, chama a atenção para o fato de que

Considerando que a morfologia nominal do português se assenta, em termos sistemáticos, apenas no acusativo latino, as vogais $a, o$ e $e$, típicas do acusativo da primeira, segunda e terceira conjugações em latim vulgar respectivamente, ganharam foro de vogais temáticas em português; por via análoga, as vogais $a, e$, e $i$, que indicam as conjugações em latim vulgar, passam a vogais temáticas verbais em português. Já os vocábulos desprovidos de vogal temática, seja por advirem de outros casos latinos (Deus), seja por terem sofrido acidentes fonológicos que elidiram a vogal temática (annelum $>$ anel) ou mesmo por serem empréstimos oxítonos terminados em vogal (rapé, sapê), são hoje entendidos como nomes atemáticos. Tais vocábulos, entretanto, inscrevem-se perfeitamente no conceito de tema predominante na gramática científica,". (Cavaliere 2000:317)

Para Carvalho (1973), essas vogais átonas finais constituem atualizadores lexicais, que, associados ao radical, permitem "atualizar o que só virtualmente é um elemento do léxico." (p. 58) Os sufixos - o e-a "funcionam em segundo lugar, cumulativamente, como morfemas de gênero.” (p. 58)

Admitido o conceito de vogal temática, temos duas grandes categorias de nomes: os temáticos, caracterizados pela presença de uma vogal temática (- $a,-e$ ou $-o$ átonos, sejam ou não oriundos do latim), e os atemáticos,

2 Citamos o artigo pela versão virtual, que não traz numeração de páginas. 
que não apresentam esse morfema (em sua maioria oxítonos terminados em vogal, como tupi, suflê, café, Pará, socó, metrô, tutu, mas também (pro)paroxítonos terminados em -is e -us (tênis, ânus, bônus, ônus), bem como em alguns outros casos (Manaus, tórax, fênix, etc.).

\subsection{Flexão nominal}

JMC considera as flexões de gênero e de número como manifestadas por uma oposição privativa, em que um elemento marcado (feminino, plural) se opõe a outro, não-marcado (masculino, singular). Em ambos os casos, os dois membros da oposição são tratados como morfemas distintos, sendo o membro não marcado representado por um morfema zero, em oposição às formas mínimas associadas ao conceito expresso pelas formas marcadas.

\subsection{Gênero natural X gênero gramatical}

Remonta à antiguidade o reconhecimento da inadequação de um critério de base sexual para estabelecimento do gênero gramatical: “...os estóicos compreenderam a operação de concordância em gênero, e perceberam a falta de correspondência entre gênero e sexo, apontando como função do artigo indicar o gênero e o número do nome." (Neves 2002: 40)

Esse reconhecimento é freqüentemente posto em destaque não só em trabalhos especializados (manuais e dicionários de lingüística, textos específicos sobre morfologia) mas também em gramáticas e textos didáticos.

Admitindo que "A flexão de gênero é exposta de uma maneira incoerente e confusa nas gramáticas tradicionais do português" (Mattoso Câmara 1970:78), JMC demonstra que outros processos tradicionalmente considerados no tratamento do gênero dos nomes nada têm a ver com processos flexionais, pertencendo a diferentes áreas da descrição científica, tais como derivação (embaixador/embaixatriz), seleção lexical (bomem/mulher), e o recurso sintático do emprego de adjetivo qualificativo (tigre fêmea).

Em sua análise, que apresenta de maneira mais desenvolvida em Mattoso Câmara 1966 (reproduzido em Mattoso Câmara 1972a), são femininos apenas os nomes marcados pelo morfema de gênero feminino, fonologicamente /-a/, quer acrescentado a nomes terminados em consoan- 
te (cantor/cantora) quer em oposição a formas em $-o$ ou $-e$, com supressão da vogal temática (menino/menina, mestre/mestra). Tal supressão, esclarece, constitui "regra morfofonológica geral, na língua portuguesa, que permeia todo o mecanismo da flexão e da derivação." (Mattoso Câmara 1969:63). Ou seja, a mesma regra que nos dá menino/menina, mestre/mestra, cantor/ cantora opera em falar $>$ falo e leite $>$ leiteiro.

O estabelecimento do gênero é descrito por JMC como determinado pelo artigo, ${ }^{3}$ explícito ou não (Mattoso Câmara 1969: 64; 1970: 81), e assim transferido para além do âmbito da morfologia, considerando o gênero imanente, intrínseco, o que significa tratá-lo como um traço semântico, paralelo a outros como [animado], [humano], [contável], etc.

O caráter masculino ou feminino da palavra está imanente na palavra e é de natureza lexical, não flexional. (Mattoso Câmara 1975:77; ênfase nossa)

Em outros termos, a flexão nominal, quando aparece, reforça apenas a expressão de uma categoria gramatical latente, que, mesmo sem essa flexão, se manifesta pela forma do artigo definido que o vocábulo nominal exige. (Mattoso Câmara 1969, 64; ênfase nossa)

Dizer que é o artigo que determina o gênero, contudo, constitui quando muito um recurso didático, posto que, como destacado na citação acima, é o artigo que assume o gênero (e número) do substantivo, o mesmo ocorrendo com outros modificadores do nome.

Em concordância com as críticas a que já nos referimos acima, JMC observa que, embora a flexão de gênero, quando aplicada a seres animados, seja usualmente associada a distinções de sexo (macho/fêmea), indica apenas uma mudança de significado no caso de itens lexicais aos quais a distinção masculino/feminino não se aplica (barco/barca, cinto/cinta, jarrol jarra ${ }^{4}$ etc.).

Considera, portanto, o gênero como "uma categoria formal para os nomes” (Mattoso Câmara 1969:62) que difere da classificação formal dos

\footnotetext{
3 A rigor esta admissão remonta a Fernão de Oliveira (1975[1536]) e a João de Barros (1971[1540]).

4 Jarra, do árabe jarrah, é primeiramente documentada como jarra, no séc. XVI. A forma jarro ocorre a partir do séc. XVII. (Cf. Cunha 1987), sendo, portanto, derivada.
} 
verbos em três conjugações por poder o gênero variar para um mesmo nome substantivo, condicionando uma especialização de sentido.

No caso dos nomes que se referem a seres vivos ( $[+$ anim $])$ essa especialização de sentido pode estar relacionada com uma diferença de sexo (gato/gata). Para os não-animados, trata-se de "uma especialização altamente cambiante" (Mattoso Câmara 1969:62). Em pares como cintolcinta, jarroljarra, pode indicar subtipo, diferença de forma ou função, etc. Contudo, pouco/pouca, pingo/pinga apresentam significação praticamente idêntica em expressões como uma pouca de..., uma pinga de... (uso praticamente restrito a Portugal), de que arrolamos alguns exemplos: ${ }^{5}$

a. "Rega-se com uma pinga de água e, depois de cozer um pouco, junta-se a cenoura em rodelas."

b. "Palestras com uma pinga de café" é o nome genérico a que obedecem as comemorações."

c. "Chegou à América em 1935 com uma pouca de roupa interior e um maço de livros."

d. "e a juventude brasileira ainda vivia os efeitos da "Era de Aquário", embora de uma forma uma pouca tardia."

Demonstra-se, assim, adequada a análise do morfema de gênero marcado como especificador semântico e não como indicador de feminino.

\subsection{Número}

A definição do número tem-se mantido a mesma desde nossos primeiros gramáticos. Fernão de Oliveira não define o conceito, por considerar que “[o] intuito desta parte da Gramática [.....] não é mais que só dar

5 Origem dos exemplos: a. Feijão verde à alentejana. Roteiro gastronômico: www.portugal.gastronomias.com/ alentejo027.html; b. SIZA, Rita. Viagem ao mundo de Pascoaes: De Vila Real a Amarante. Instituto Camões, Noticiário Cultural. Arquivo, 05-05-1998; c. RODRIGUES, Rogério. José Ribeiro Miguéis: um baú de sonhos com um grande espólio por inventariar. Lisboa: Jornal de Letras 6, 12 de Maio de 1981; d. "Texto publicado originalmente na revista ShowBizz, edição número 184, de novembro de 2000." [reproduzido em http:// www.senhorf.com.br/sf3/secreta /lpsrar/spectrum.htm]. 
notícia das vozes, e não definições ou determinadas declarações das coisas." (Oliveira 1536/1975:114).

João de Barros, contudo, já define: "Número em o nome é aquela distinçam per que apartamos um de muitos. E ao número de um chamam os gramáticos singular, e ao de muitos plurár." (Barros 1540/1971:309)

Essa definição, em outras formulações, vem se repetindo desde então até a atualidade.

Distinguindo significação e forma, JMC esclarece que o número “[c]onceptualmente, é a oposição entre um único indívduo e mais de um indivíduo. Morfologicamente é a ausência de $-\mathrm{s}$ final no singular e sua presença no plural.” (Mattoso Câmara 1975:75)

$\mathrm{Na}$ análise tradicional, o singular, sem marca característica, se opõe a um plural marcado pelos sufixos $-s$ e -es. Outros casos, como o plural das palavras em $-l$, em ditongo nasal, etc. costumam ser simplesmente relacionados, mas não analisados.

Como no caso do gênero a análise de JMC trata também o número como oposição privativa, em que o membro marcado, o plural, se opõe a um membro não-marcado, o singular, representado por um morfema zero.

A marca de plural é fonologicamente uma consoante fricativa /-s/, com alomorfes dependentes do contexto fonológico, admitindo palatalização na fala de Portugal, do Rio de Janeiro e de outras regiões.

Demonstra que o suposto plural em -es decorre da recuperação da vogal temática $-e$ da maioria das palavras terminadas em consoante no singular, adicionando-se a ela o morfema do plural, com eventual operação de processos morfofonológicos.

$\mathrm{Na}$ análise dos outros casos, JMC põe em evidência os processos morfofonológicos envolvidos, enfatizando a regularidade de formação do plural, sempre com o sufixo/-s/, exceto no caso de paroxítonos terminados em /-is/ átono ou o de certos monossílabos em /-s/, em que ocorre um alomorfe zero do morfema de plural. Para sua análise desses casos, parte de formas teóricas em grande parte dedutíveis sincronicamente. Apenas no caso das palavras em - ão recorre a uma análise mais complexa, que parte da consideração das formas plurais. 
Difere, portanto, significativamente da análise tradicional por, ao postular um único sufixo, demonstrar a unicidade do processo de flexão de número.

\section{Outras idéias}

A análise de JMC constitui considerável progresso em relação à análise tradicional, por considerar a expressão oral, por incorporar fatores antes não considerados e também por introduzir considerável simplicidade na descrição do processo.

Essa análise teve forte repercussão, e reflete-se na quase totalidade dos trabalhos sobre morfologia do português publicados posteriormente, entre 1973 e 2000, ${ }^{6}$ tornando-se a análise padrão da flexão nominal em português, como destaca Rocha ao discutir a distinção entre flexão e derivação, afirmando basear-se em Mattoso Câmara (1970) "pelo fato de essa obra ter-se constituído em um marco para o estudo da morfologia portuguesa no Brasil e pelo fato de as idéias desse autor serem ainda hoje um ponto de referência para os estudos gramaticais brasileiros." (Rocha 1998:193)

Outros pontos de vista, contudo, poderiam ser adotados, aprofundando a análise

Assim, por exemplo, Bloomfield (1933:178) já considerava, para o inglês, o plural dos nomes e as diferentes formas verbais como palavras diferentes:

In our school tradition we sometimes speak of forms like book, books, or do, does, did, done as "different forms of the same word." Of course, this is inaccurate, since there are differences of form and meaning between the members of those sets: the forms just cited are different linguistic forms and, accordingly, different words.

Hockett (1959: 230) trata o gênero como intrínseco: "Nouns belong to a gender; some adjectives are inflected for gender."

6 Back, Heckler \& Massing (1973); Carone (1994); Freitas (1981); Kehdi (1990); Laroca (1994); Macedo (1976); Monteiro (2002); Rocha (1998); Rosa (2000); Sandman (1992); Silva \& Koch (1983); Zanotto (1986). 
Gleason, da mesma maneira, considera o gênero inerente ao nome, admitindo flexão apenas para os adjetivos:

In nouns, gender is commonly an inherent feature of each stem. That is, nouns are not inflected for gender, but each noun has a characteristic gender. In those languages with a well-developed concord system, adjectives are usually inflected for gender; that is, no adjective has an inherent gender, but may be inflected to produce a form for each gender. In many instances this is a useful basis for distinguishing between these two parts of speech. (Gleason 1961:228-9)

O mais completo tratamento de que dispomos para o gênero é Corbett (1991), que considera o gênero "the most puzzzling of grammatical categories" (p. 1), e a ele dedica todo um volume, baseado na análise de mais de 200 línguas (porém com apenas breve referência à língua portuguesa).

Em textos publicados desde o final dos anos 60, o lingüista português José Gonçalo Herculano de Carvalho já tratava o gênero dos nomes em português como derivação e não flexão (cf. Carvalho 1969: 323), em virtude de suas características específicas, posição que reafirma mais tarde:

No português são, como sabemos, palavras flexionadas o substantivo (com flexão de número, mas não de género, o adjectivo (incluindo o particípio em função adnominal) e com este quase todos os pronomes, o artigo e os numerais ordinais (com flexão de género e número), uma parte dos numerais cardinais (com variação de género) e finalmente o verbo. (Carvalho1974: 601; ênfase nossa)

Em artigo significativamente intitulado “Gênero?”, John Martin (1975) contesta a propriedade dos termos masculino e feminino na caracterização das palavras em português, baseando-se sobretudo em exemplos como um sorvete seria ótimo, está cheio de crianças na praia, aqui é bom, etc., em que a forma do adjetivo não é determinada por um substantivo, concluindo que

No lugar de "gênero", então, fica o conceito de adjetivos marcados ou não marcados. Os marcados correspondem aos "femininos" da gramática escolar, e aparecem somente quando o adjetivo está relacionado a um substantivo marcante. Os não marcados aparecem EM TODAS AS OUTRAS CIRCUNSTÂNCIAS, haja ou não um substantivo a eles relacionado. É este último fato que determina que o assunto não seja uma mera questiúncula terminológica, pois as conclusões dele decorrentes transformam dum modo essencial nossa maneira de encarar a categorização dos substantivos e o fenômeno da concordância adjetiva. (Martin 1975:8) 
Não discute, contudo, tratar-se ou não de flexão

É curioso notar que esse artigo parece não ter tido a influência que se poderia esperar. Dos doze manuais de morfologia por nós consultados, ${ }^{7}$ apenas Rosa (2000) o inclui em sua bibliografia.

Posição semelhante é adotada por Jensen em relação ao latim, em caso perfeitamente análogo ao que ocorre em português:

Because it features in agreement rules, gender is normally considered inflectional in Latin, yet it functions derivationally in such pairs as cervus (masculine) 'stag' cerva (feminine) 'doe' (Jensen 1990:116)

A pioneira análise de Herculano de Carvalho não se reflete nos manuais de morfologia publicados entre nós desde então, apenas vindo a ser retomada por Evanildo Bechara no final dos anos 90 (Bechara 2000:132 [C 1999]).

Bem mais recentemente, Rosa (2000), baseando-se em Bechara, adota a mesma posição, que, reconhece, "vem ganhando adeptos nas descrições do português" (p. 125). Em trabalho até o momento apenas veiculado pela Internet ("O problema da flexão de gênero"), José Pereira da Silva (2004) retoma esse ponto de vista, analisando as questões envolvidas e arrolando autores que adotam tal posição.

Obviamente, muito dessa discussão depende de como se definem os conceitos de palavra, flexão e derivação, questão que extrapola o âmbito deste trabalho. $\mathrm{Na}$ interpretação de Bybee (1985, Cap. 4) flexão e derivação seriam não conceitos radicalmente opostos, mas sim extremos numa escala contínua (ou seja, integrariam uma oposição gradual).

Ainda assim, contudo, a análise permite novos questionamentos, se levarmos em consideração características do uso real da língua em suas diversas modalidades.

\subsection{Morfema zero}

Tanto na análise do gênero quanto na do número, a análise de JMC envolve a consideração de um morfema zero. Esse conceito, apesar de sua

7 Ou princípio da parcimônia, atribuído a Guilherme de Occam (ca. 1285-1349). 
indiscutível aplicação e conveniência na análise lingüística, sempre se demonstrou uma faca de dois gumes, a ser utilizada com extremo cuidado.

A possibilidade de criar livremente morfemas que não se manifestam para obter a desejada simetria na análise é altamente tentadora, e requer do analista a estrita observância da chamada navalha de Occam, ${ }^{8}$ princípio segundo o qual não se devem criar entidades além do absolutamente necessário.

Gleason (1961:76), que reconhece o conceito de alomorfe zero, embora como "merely a convenient device", opõe-se ao estabelecimento de um morfema zero:

That is, one in which there is no overt allomorph whatever. To do so is quite unnecessary and will generally lead to increased complexity of statement, the precise opposite of our desired goal. Moreover, it is logically indefensible. If we are to make such free use of zero, there is no definable place to stop. (Gleason 1961:76)

A fragilidade desse conceito é destacada por Matthews (2000) "These concepts were never universally accepted even within the North American school, whose model this was". Discute ainda as implicações de se adotar esse conceito, ressaltando que "to say that something is not marked is one thing; to say that it is marked by zero is another." (Matthews 2000:123-124).

Mais recentemente, Mel'cuk (1999) dedica extenso artigo ao conceito de morfema zero e sua aplicação na análise lingüística. Estabelece um princípio em que se formulam as condições necessárias para a introdução de um zero lingüístico e considera diversos tipos de signos zero. Observa que "Generally speaking, one should not look for a zero marker where one could see a real, 'physical' i.e. overt difference: a zero sign must be exclusive as a possible carrier of the information in question or there is no zero sign." (p. 6)

Não adotando o conceito de morfema zero, deveremos recorrer a outro tipo de análise que permita descrever adequadamente os fenômenos considerados, o que nos leva a ter de reconsiderar os procedimentos adotados.

8 A citação incluída no trecho é de Eduardo Carlos Pereira, Gramática expositiva: Curso superior. São Paulo: Nacional, 1918. p. 83. 


\section{Revendo os conceitos}

Acostumados que estamos a certos aspectos da análise tradicional, dificilmente os questionamos, aceitando-os como propostos e sem por vezes nos darmos conta de que talvez não representem mais do que um costume, uma tradição, como mencionam alguns autores.

Habituamo-nos a considerar o gênero em português como um fenômeno flexional. Embora nossas gramáticas nem sempre definam com clareza o que tomam por flexão, é uma tradição afirmar que "os substantivos mudam em sua terminação, isto é, mudam de flexão, para indicarem os acidentes de GÊNERO, NúMERO e GRAU (Rosa 2000:125; ênfase nossa).

Number is familiarly thought of as a contrast between one category indicating a single individual and another indicating two or more. These are traditionally designated singular and plural. These names are indicated to suggest the "meanings" of these categories." (Gleason 1961:223; ênfase nossa).

Nas descrições lingüísticas, um dos gêneros é tomado como base do sistema (caso marcado), sendo os outros gêneros descritos relativamente a este (casos marcados): assim, em português, o feminino é geralmente descrito por uma variação morfológica do masculino, tomado como base. (Dubois et al 1995:302; ênfase nossa).

\subsection{Gênero}

Como dissemos acima (em 1.3 Gênero natural X gênero gramatical), a terminologia adotada para a descrição do gênero enfatiza a relação machol fêmea, implicando a predominância desse critério biológico, sem que se justifique tal posição. Mais ainda, Rocha (1998) relata pesquisa anterior ${ }^{10}$ em que se constatou que apenas $4,5 \%$ dos substantivos no corpus analisado apresentavam feminino característico. A grande maioria dos substantivos, por conseguinte, apresenta gênero fixo, não sujeito ao que se costuma considerar flexão. Convém ainda lembrar que muitos substantivos apresentam uma única forma para ambos os gêneros (intérprete, contribuinte, analista, etc.)

9 A referência no texto a Rocha (1981) não corresponde a nenhum item nas referências bibliográficas do livro.

10 A referência no texto é a Rocha, L. C. A. Flexão e Derivação no Português. Belo Horizonte NAPq /FALE/UFMG, 1994. 
Se a distinção com base no sexo não só não é o critério predominante, como constitui apenas um caso particular, aplicado a um número restrito de palavras, seria preferível abandonar a dicotomia masculino/feminino e considerar a ocorrência de apenas um morfema derivacional, que denominaremos especificador ( $\{\mathrm{ESP}\})$, cujo acréscimo tem por função indicar especificação semântica da natureza variável, diferente para diferentes vocábulos ou classes de vocábulos. Tal interpretação nos proporciona uma análise ao mesmo tempo mais simples e mais precisa da função do gênero na estrutura da língua. Permite ainda melhor compreensão da razão de a forma não marcada (o masculino) ser a empregada para generalizar, abrangendo toda uma classe, em frases como "O sertanejo é acima de tudo um forte" (Euclides da Cunha, Os sertões, Cap. III), evitando-se, em conseqüência, interpretações que procuram vincular esse fenômeno gramatical a noções de ordem sociológica.

Kehdi (1990) observa que

o povo, em sua linguagem espontânea, cria formas masculinas sempre em -o; p. ex. faz-se corresponder ao feminino coisa o masculino coiso, inexistente na língua culta. São também dignas de nota formações como corujo, crianço, madrasto. Essas observações conduzem-nos à conclusão de que -o está intimamente associado à noção de masculino: a flexão de gênero não se reduz a uma oposição $\varnothing /-a$, e, sim, a uma oposição $-o$ / -a (p. 30-31)

Embora se trate de uma análise plausível para o que seria um fenômeno análogo à etimologia popular, é difícil verificar se se trata de uma reação natural, por analogia, ou de influência do uso dos termos masculino e feminino, aprendidos na infância.

De qualquer forma, não deveria surpreender o fato de que essa interpretação popular venha a divergir, mesmo radicalmente, do resultado de uma análise teórica, baseada em critérios fundamentados e explícitos e não em uma simples suposição.

\subsection{Número}

A definição de número como a oposição um/mais de um não resiste a uma análise mais minuciosa do uso real das formas ditas singular e plural. 
O chamado singular, a rigor, não especifica unicidade, tanto assim que é usado como termo genérico, significando "todo e qualquer membro da categoria X", como no conhecido slogan "Livro, presente de amigo", ou na igualmente conhecida afirmativa do carnavalesco Joãozinho Trinta "Quem gosta de miséria é intelectual. Pobre gosta de luxo."

Esse uso, nem sempre é considerado nas gramáticas, embora muitas mencionem o emprego do singular (em geral também "masculino", ou seja [-ESP]) para se referir a uma espécie tomada como um todo. Exemplos podem ser encontrados com facilidade, principalmente na fala e na escrita menos formal.

O conceito de número é analisado detalhadamente em Corbett (2000), com base em mais de duas centenas de línguas, o que lhe permite estabelecer interessante tipologia de sistemas de número, demasiado ampla para ser considerada aqui.

O que efetivamente indica que a referência é a um único elemento é a presença de um numeral (esperei por uma hora), um artigo, definido ou indefinido (li o livro, li um livro), um pronome demonstrativo (este livro é caro) ou indefinido (qualquer pessoa sabe disso).

Depreende-se, portanto, que o chamado singular seria mais adequadamente definido como não-referência ao número, enquanto que a marca de plural indica referência a um número indefinido, o "mais de um" da definição tradicional.

Teríamos assim um único morfema $\{\mathrm{NUM}\}$, que abrange, portanto, um ou vários membros de uma classe (criança $\{$-NUM $\} /$ crianças $\{+N U M\})$ ou uma classe como um todo (criança (-NUM) gosta de brinquedo).

Ao contrário do gênero, o número não é inerente ao nome - decorre de uma escolha baseada em fatores pragmáticos e na decisão de incluir ou não referência ao número.

Assim, por exemplo, em "Livro, presente de amigo" o que se tem é o uso do chamado singular para indicar que a referência é apenas ao conceito de livro, independentemente de qualquer menção de número., equivalendo a "um ou mais objetos da classe livro são presente de quem é amigo". 
Em Buscar menino no colégio (título de Saraiva 1997), o emprego da forma menino abrange duas generalizações: não se trata necessariamente de um único menino, nem se exclui a possibilidade de se tratar de menina(s) ou de um grupo misto, nem Equivale, portanto, a dizer "buscar criança(s) no escola”. E nem se trata necessariamente de um único colégio.

O mesmo se aplica a exemplos como "Professor brasileiro ganha mal." (Diário Catarinense, 3-10-2002), "Aparece vendedor de tudo quanto é canto." (ouvido em conversação) ou a inúmeros outros semelhantes.

\subsection{Quantos morfemas?}

Se caracterizarmos o gênero como um processo derivacional e reconhecermos ser inadequada a terminologia tradicional, baseada em uma distinção biológica, poderemos considerar não uma oposição privativa mas sim um único morfema aditivo, cuja função é a de especificar um significado particular. Poder-se-ia manter a denominação gênero, dissociando-a contudo das noções de masculino e feminino. Preferimos aqui denominá-lo especificador (representado por $\{\mathrm{ESP}\}$ ), interpretando os nomes como caracterizados por um traço $[\alpha$ ESP $]$, em que o valor de $\alpha$ permite determinar a forma que a palavra tomará, especificando-se no léxico se ocorre o acréscimo do alomorfe /-a/ (menino/menina), outro processo fonológico (valentão/ valentona), acréscimo de outros sufixos derivacionais (imperador/imperatriz, príncipe/princesa) ou ainda formas particulares, de ocorrência restrita (leão/ leoa, judeu/judia).

No caso de seleção lexical (bomem/mulher, bode/cabra, etc.) obviamente não está em jogo nenhum critério gramatical, mas sim a opção pela palavra adequada, determinada pragmaticamente.

É essa característica dos nomes substantivos que vai determinar a concordância, que se manifesta pela seleção da forma adequada dos modificadores do substantivo (artigos, pronomes demonstrativos e indefinidos, adjetivos), estes sim dotados de flexão.

Rosa (2000) sugere a possibilidade de se tratar também o número como um processo derivacional: 
Levada às últimas conseqüências, a determinação nos dá como flexional o Número no adjetivo, mas não no nome, o que foi ressaltado por Rocha (1994): 14 - ênfase no original): "Se alguém diz: - Eu não tenho amigos, eu tenho um amigo, não é a natureza da frase, a estrutura da oração que determina o emprego da forma singular ou plural do substantivo. É a situação. ${ }^{10}$ (Rosa 2000:126)

Assim sendo, torna-se evidente que também no caso do número dos substantivos o que ocorre é derivação e não flexão.

Se tanto o gênero quanto o número forem tratados como processo derivacional, e se levarmos em consideração o fato de que o masculino e o singular não se manifestam, não há motivo para a manutenção das dicotomias masculino/feminino e singular/plural.

\section{Conclusão}

Adotar os critérios expostos acima significa reinterpretarmos o sistema tradicional de quatro morfemas como constituído por apenas dois morfemas derivacionais aditivos, $\{\mathrm{ESP}\}$ e $\{\mathrm{NUM}\}$ que se podem acrescentar ao substantivo, não sujeito a flexão. Apresentarão flexão apenas os modificadores do substantivo.

Por se tratar de processos derivacionais, a variação de forma do substantivo não estará sujeita à obrigatoriedade associada ao conceito de flexão. A aplicação das regras de concordância é de âmbito variável em função do nível de linguagem considerado. $\mathrm{Na}$ variedade socialmente privilegiada denominada "norma culta" ou "língua padrão", todos os modificadores do substantivo devem concordar com ele quanto à especificação ( $\{ \pm$ ESP $\})$ e quanto à referência ao número $\left(\left\{ \pm_{\mathrm{NUM}}\right\}\right)$. Já em outras variedades o funcionamento do sistema é diverso. Devido à existência de extensa bibliografia sobre questões de variação em português, limitamo-nos aqui à menção de Campos \& Rodrigues (1996) que analisam a flexão nominal de número na língua falada, em um corpus extraído do material do Projeto NURC (Projeto de Estudo da Norma Lingüística Urbana Culta), compreendendo 450 minutos de gravação.

E-mail: gcintra@bn.com.br 


\section{REFERÊNCIAS}

Almeida, N. M. de.1963. Gramática Metódica da Língua Portuguesa. São Paulo: Saraiva

Back, S.; Heckler, E. \& MAssing, E. R. 1973. Estrutura da palavra. Estudos Leopoldenses, 25: 3-75.

Barros, J. de. 1540. Grammatica da Lingua Portuguesa com os Mandamentos da Santa Madre Igreja. In Barros 1971.

1971. Gramática da Língua Portuguesa. Cartinha, gramática, dialogo em louvor da nossa linguagem e diálogo da viciosa vergonha. Reprodução facsimilada, leitura, introdução e anotações por Maria Leonor Carvalhão Buesco. Lisboa: Faculdade de Letras da Universidade de Lisboa.

Basílio, M. 1999. A morfologia no Brasil: indicadores e questões. DELTA, 15/Especial: 53-70.

Bechara, E. 2000. Moderna Gramática Portuguesa. Ed. rev. e amp. Rio de Janeiro: Lucerna [C 1999].

Bloomfield, L. 1933. Language. New York: Henry Holt.

Bybee, J. L. 1985. Morphology: a Study of the Relation between Form and Meaning. Amsterdam: John Benjamins.

Campos, O. G. L. A. S. \& Rodrigues, A. 1996. Flexão nominal: indicação de pluralidade no sintagma nominal. In Ilari, R. (org.) Gramática do Português Falado. Vol. II: Níveis de análise lingüística. 3a. ed. Campinas: Ed. da UNICAMP.

Carone, F. de B. 1994. Morfossintaxe. 4a. ed. São Paulo: Ática.

Carvalho, J. G. H. de 1969. Gênero. In Verbo Enciclopédia Luso-Brasileira de Cultura, Lisboa vol. 9; p. 320-324.

1973. Atualizadores léxicos. Vozes, 67/5: 49-60.

1974. Teoria da Linguagem. Vol. 2 (2a. tir., emend.) Coimbra: Atlântida.

Cavaliere, R. 2000. Fonologia e Morfologia na Gramática Científica Brasileira. Niterói: EdUFF.

Corbett, G. G. 1991. Gender. Cambridge: University Press [repr. 1955]. 2000. Number. Cambridge: University Press.

Cunha, C. F. \& L. F. L. Cintra. 1985. Nova Gramática do Português Contemporâneo. Rio de Janeiro: Nova Fronteira.

Cunha, A. G. 1987. Dicionário Etimológico Nova Fronteira da Língua Portuguesa. 2a. ed. Rio de Janeiro: Nova Fronteira. 
Duarte, P. M. T. 2002. Do estatuto mórfico da vogal temática e do morfema de gênero em português. Philologus 23. Rio de Janeiro: CiFEFiL, maio/ago.2002, p. 112-130. [também disponível em www.filologia.org.br/ revista/artigo/7(23)06.htm].

Dubois, J. et al. 1995. Dicionário de Lingüística. 5a. ed. São Paulo: Cultrix.

Freitas, H. R. de. 1981. Princípios de Morfologia. 2a. ed. Rio de Janeiro: Presença.

Gleason Jr., H. A. 1961. An Introduction to Descriptive Linguistics. New York: Holt, Rinehart \& Winston.

Hocketт, C. F. 1959. A Course in Modern Linguistics. 2a. ed. New York: Macmillan.

Jensen, J. T. 1990. Morphology: Word Structure in Generative Grammar. Amsterdam: John Benjamins.

Kehdi, V. 1990. Morfemas do Português. 3a. ed. São Paulo: Ática [C) 1988].

Laroca, M. N. de C. 1994. Manual de Morfologia do Português. Campinas: Pontes / Juiz de Fora: UFJF.

Macedo, W. 1976. Elementos para uma Estrutura da Língua Portuguesa. 2a. ed. Rio de Janeiro: Presença.

Martin, J. W. 1975. Gênero? Revista Brasileira de Lingüística, 2/1: 3-8.

Mattoso CÂmara Jr., J. M. 1941. Princípios de Lingüística Geral. Rio de Janeiro: F. Briguiet

1954. Princípios de Lingüística Geral. 2a. ed. rev. e aum. Rio de Janeiro: Acadêmica.

1959. Princípios de Lingüística Geral. 3a . ed. rev. Rio de Janeiro: Acadêmica.

1964. Princípios de Lingüística Geral. 4a. ed. Rio de Janeiro: Acadêmica.

1966. Considerações sobre o gênero em português. Estudos Lingüísticos, 1(2): 1-9 [reproduzido em Mattoso Câmara Jr., J. 1972a, p. 115-129].

1969. Problemas de Lingüística Descritiva. Petrópolis: Vozes.

1970. Estrutura da Língua Portuguesa. Petrópolis: Vozes.

1972a. Dispersos. Rio de Janeiro: Fundação Getúlio Vargas.

1972b. The Portuguese Language. Chicago: Chicago University Press. 


\section{Padrão.}

1975. História e Estrutura da Língua Portuguesa. Rio de Janeiro:

Matthews, P. H. 2000. Morphology: an Introduction to the Theory of

Word Structure. 2a. ed. Cambridge: University Press [C) 1974].

Mel'cuK, I. M. 1999. Zero Sign (in Morphology). The Fourth International

Symposium on Language, Logic and Computation, Batumi 1999.

[disponível em: http://www.illc.uva.nl/ Borjomi/Proceedings/Mel.pdf].

Monteiro, J. L. 2002. Morfologia Portuguesa. 4a. ed. Campinas: Pontes.

Naro, A. J. 1976a. Tendências atuais da lingüística e da filologia no Brasil.

In Naro 1976b, p. 67-114.

(org.) 1976b. Tendências Atuais da Lingüística e da Filologia no

Brasil. Rio de Janeiro: Francisco Alves.

Neves, M. H. de M. 2002. A Gramática: História, Teoria e Análise, Ensino.

São Paulo: Ed.da UNESP.

Oliverra, F. de. 1536. Grammatica da lingoagem portuguesa. In Oliveira 1975.

1975. A gramática da linguagem portuguesa. Introdução, leitura e notas por Maria Leonor Carvalhão Buescu. Lisboa: Imprnesa Nacional, Casa da Moeda.

Rocha, L. C. de A. 1998. Estruturas Morfológicas do Português. Belo Horizonte: UFMG.

Rosa, M. C. 2000. Introdução à Morfologia. São Paulo: Contexto.

Sandman, A. J. 1992. Morfologia Lexical. São Paulo: Contexto.

Saraiva, M. E. F. 1997. Buscar Menino no Colégio. Campinas: Pontes.

Silva, M. C. P. Sousa e \& I. G. V. Koch. 1983. Lingüística Aplicada ao Português: Morfologia. São Paulo: Cortez.

Trubetzkoy, N. S. 1949. Principes de Phonologie. Paris: Klincksieck [reimpr. 1976].

Zanotto, N. 1986. Estrutura Mórfica da Língua Portuguesa. Caxias do Sul: EDUCS. 